\title{
Traumatic brain injury registry: Need of the hour
}

India contributes and considerably impacts global health indicators. A remarkable progress has been made in recent decades to reduce the number of deaths on road, though it is still one of the ten leading causes worldwide. A large proportion of road crashes are preventable with capacity building in prehospital care, development of dedicated trauma care center, and functional neurotrauma care practices at non-neurosurgical health facilities with the potential to reduce the burden of needless morbidity, disability, and mortality. Traumatic brain injury (TBI) is one of the critical causes of death and poses a global public health problem affecting billions to outshine quite a few causes of mortality and morbidity by the end of the present decade. In India, trustworthy information on TBIs and their predictable outcomes are still unavailable in the absence of a comprehensive national level trauma and/or TBI database. Yet, TBI has been recognized as the research interest by a good number of Indian doctors with growing efforts to address these preventable events on a priority basis. Further, it is extremely encouraging that a systematic research-based data collection drive on injuries, in general, and TBI-related research, in particular, have been gaining momentum at different corners of our country. Experience from developed countries has proved beyond doubt that "Trauma Registries" are an integral part of the methodology of trauma systems for the systematic collection of data and concurrent evaluation of outcome and they have been an established instrument in trauma care practices. Thus, a trauma registry will provide a comprehensive instrument to process data and analyze the epidemiological and research gap between developed countries and India. ${ }^{[1-5]}$

Globally, trauma registries have become important sources of data for TBI research. Yet, a dedicated TBI registry is able to delineate more precise evidence on effective interventions to clearly demark timelines for implementation, monitoring, and evaluation, and scale up futuristic plans. In the downstream effects, TBI registry in our country will help in reducing the burden, and it is expected that all stakeholders working toward improving health will stridently work for an effective implementation with a systematic plan for monitoring and evaluation with a list of dashboard indicators. With our commitment to end preventable TBIs, a clear understanding is needed for risk factors of all these deaths and disabilities. In addition, a concerted effort toward translating these commitments into meaningful changes should have been an important part of TBI registry agenda. A major initiative, launched by Dr. Amit Agarwal by indigenously structured "TBI registry," has been well piloted at the Narayana Medical College, Nellore, and presented at NIMHANS at NEUROTRAUMA 2015. This ongoing "TBI registry" has been designed to serve a number of purposes, including quality of intervention, prehospital injury prevention, health service research, and in the long run countrywide policy development in launching a national-level TBI registry. Yet, there is always an urgent need to find a scope to improve any TBI registry, such as consistency in quality and type of data by dedicated personnel, addition of value to registry with more data pertaining to long-term and functional outcomes, information on prehospital care and emergency medical services, and complications as well as other obstacles born out of logistics and other measures that augment the efficacy of registry data in clinical and epidemiologic translational researches. ${ }^{[6]}$

Every effort must be made to address avoidable deaths to overcome barriers for the vulnerable sections of society by improving access to health care by systematic data collection in the first place. Government machinery with collaboration from all other stakeholders needs to provide sincere efforts toward improving safety by stepwise sensitization and harness the strengths of professional bodies, nongovernmental organizations, corporate sector, and social activists, among others. Dedicated efforts are crucial to overcome barriers at service-community level with socioeconomic upgradation, effective communication and infrastructure development on one hand and capacity building on the other. Fortunately, various efforts have demonstrated the political commitment to recognize trauma as a national development necessity. Trauma as well as TBI registry needs substantial restructuring for true representation of the incredible problem. The utility of a TBI registry is directly related to the constituents and correctness of the data entry by dedicated trained personnel. The rationale behind the establishment of these registries is identifying injured to facilitate and coordinate continuum of care till their rehabilitation and other needed services, to gather data for injury prevention and control, to gather data for 
health-care planning, and to the evaluation of services for injured persons. The world shall be looking at the Indian experience in the days to come. The strategic plan that is well outlined in the above-mentioned indigenous TBI registry will stimulate others to determine the success stories of limiting TBI-related misfortunes.

\section{Ranabir Pal}

Department of Community Medicine, Andaman and Nicobar Islands Institute of Medical Sciences, Port Blair, Andaman and Nicobar

\section{Address for correspondence:}

Dr. Ranabir Pal,

Department of Community Medicine, Andaman and Nicobar Islands Institute of Medical Sciences, Port Blair - 744 104, Andaman and Nicobar. E-mail: ranabirmon@yahoo.co.in

\section{References}

1. Vyas D, Hollis M, Abraham R, Rustagi N, Chandra S, Malhotra A, et al. Prehospital care training in a rapidly developing economy: A multi-institutional study. J Surg Res 2016;203:22-7.

2. Agrawal A, Galwankar S. What's new in emergencies, trauma and shock? Traumatic Brain Injury Research in India: Getting shape, taking momentum. J Emerg Trauma Shock 2015;8:129-30.

3. Agrawal A, Munivenkatappa A, Shukla DP, Menon GR, Alogolu R, Galwankar S, et al. Traumatic brain injury related research in India: An overview of published literature. Int J Crit Illn Inj Sci 2016;6:65-9.
4. Agrawal A, Munivenkatappa A, Pal R, GalwankarS, Salaza LR, Rubiano AM, et al. Traumatic brain injury registry: Sharing the pilot study experience to foster a multicenter project on traumatic brain injury core data. Indian J Neurotrauma 2016. Doi: http://dx.doi.org/10.1055/s-0036-1586486.

5. Agrawal A, Kakani A, Baisakhiya N, Galwankar S, Dwivedi S, Pal R. Developing traumatic brain injury data bank: Prospective study to understand the pattern of documentation and presentation. Indian J Neurotrauma 2012;9:87-92.

6. Zehtabchi S, Nishijima DK, McKay MP, Mann NC. Trauma registries: History, logistics, limitations, and contributions to emergency medicine research. Acad Emerg Med 2011;18:637-43.

This is an open access article distributed under the terms of the Creative Commons Attribution-NonCommercial-ShareAlike 3.0 License, which allows others to remix, tweak, and build upon the work non-commercially, as long as the author is credited and the new creations are licensed under the identical terms.

\begin{tabular}{|l|l|}
\hline \multicolumn{2}{|c|}{ Access this article online } \\
\hline Quick Response Code: & Website: \\
\hline & www.ruralneuropractice.com \\
\hline & \\
\hline & \\
\hline
\end{tabular}

How to cite this article: Pal R. Traumatic brain injury registry: Need of the hour. J Neurosci Rural Pract 2016;7:483-4.

\section{"Quick Response Code" link for full text articles}

The journal issue has a unique new feature for reaching to the journal's website without typing a single letter. Each article on its first page has a "Quick Response Code". Using any mobile or other hand-held device with camera and GPRS/other internet source, one can reach to the full text of that particular article on the journal's website. Start a QR-code reading software (see list of free applications from http://tinyurl.com/ yzlh2tc) and point the camera to the QR-code printed in the journal. It will automatically take you to the HTML full text of that article. One can also use a desktop or laptop with web camera for similar functionality. See http://tinyurl.com/2bw7fn3 or http://tinyurl.com/3ysr3me for the free applications. 